\title{
PENGARUH PENYULUHAN TENTANG ANEMIA TERHADAP PENGETAHUAN, SIKAP DAN KEPATUHAN IBU HAMIL DALAM MENGKONSUMSI TABLET BESI DI KLINIK BUMI SEHAT BAHAGIA KOTA BANDUNG 2020
}

\author{
Yeti Hernawati \\ Dosen Program Studi Sarjana dan Profesi Kebidanan STIKes Dharma Husada Bandung \\ hernawati.yeti@gmail.com
}

\begin{abstract}
Abstrak
Penyuluhan merupakan salah satu strategi pemerintah dalam upaya pencegahan/ tindakan preventif yang dilakukan guna membatasi terjadinya kejadian yang tidak diinginkan. Penyuluhan adalah suatu bentuk keterlibatan seseorang untuk melakukan komunikasi informasi secara sadar dengan tujuan membantu sesamanya memberikan pendapat sehingga bisa membuat keputusan yang benar, dalam penelitian ini dilakukan penyuluhan tentang anemia pada ibu hamil yang bertujuan untuk mengetahui perubahan pengetahuan, sikap dan kepatuhan ibu hamil dalam mengkonsumsi tablet besi di Klinik Bumi Sehat Bahagia , Kota Bandung. Jenis penelitian ini berupa quasi experimental dengan pendekatan prospektif. Seluruh populasi berjumlah $91 \mathrm{ibu}$ hamil dan didapati sampel sebanyak $32 \mathrm{ibu}$ hamil (purposive sampling) dengan inklusi dan eksklusi yang telah ditentukan oleh peneliti. Instrumen ini menggunakan kuesioner. Analisis dalam penelitian menggunakan univariat dan bivariat menggunakan uji regresi linier. Hasil univariat menunjukkan 93,8\% memiliki pengetahuan yang meningkat, sedangkan $3.1 \%$ memiliki pengetahuan yang tetap dan menurun, sikap ibu hamil 84,4\% meningkat, sedangkan $25,6 \%$ dengan sikap menurun, dan hasil kepatuhan ibu hamil yaitu $84,4 \%$ patuh sedangkan 15,6\% ibu hamil tidak patuh dalam mengkonsumsi tablet besi. Hasil analisis bivariat menunjukkan bahwa ada pengaruh penyuluhan anemia terhadap pengetahuan, sikap dan kepatuhan ibu hamil karena $\mathrm{p}<0,05$. Kesimpulannya adalah adanya pengaruh penyuluhan tentang anemia terhadap pengetahuan, sikap dan kepatuhan ibu hamil dalam mengkonsumsi tablet besi di Puskesmas Talagabodas. Oleh karena itu, diharapkan penyuluhan anemia ini dapat menjadi suatu tindakan preventif yang berkelanjutan dan dapat memberikan perubahan perilaku menjadi lebih baik lagi.
\end{abstract}

Kata kunsi $\quad$ : Penyuluhan Anemia, Pengetahuan, Sikap, Kepatuhan, Tablet Besi

\section{PENDAHULUAN}

SDGs (Sustainable Developmnt Goals) adalah sebuah program pembangunan berkelanjutan dimana didalamnya terdapat 17 tujuan dengan 169 target yang terukur dengan tenggat waktu yang ditentukan. SDGs bertujuan untuk pembangunan bersama sampai tahun 2030 menggantikan MDGs yang sudah berakhir pada tahun 2015. Salah satu target yang harus dipenuhi dalam tujuan ketiga yakni kesehatan yang baik adalah mengurangi sepertiga angka kematian premature akibat penyakit tidak menular. ${ }^{(4)}$

Penyebab utama kematian ibu diantaranya karena perdarahan, eklamsia, dan infeksi. ${ }^{(1)}$ Perdarahan antepartum dan post partum lebih sering dijumpai pada wanita yang anemis dan lebih sering berakibat fatal. Anemia meningkatkan frekuensi terjadinya komplikasi pada saat hamil dan persalinan, resiko 
JURNAL SEHAT MASADA VOLUME XVI

kematian maternal, prematuritas, BBLR, dan kematian perinatal.

Berdasarkan hasil Riset Kesehatan Dasar (Riskesdas) tahun 2018, prevalensi anemia di Indonesia yaitu 21,7\%. Data Survey Kesehatan Rumah Tangga (SKRT) tahun 2018 menyatakan bahwa prevalensi anemia pada ibu hamil di Indonesia adalah 50,5\%. ${ }^{(7)}$ Menurut Dinas Kesehatan Provinsi Jawa Barat ibu hamil yang mengalami anemia adalah 57,1\% dan di Kota Bandung pada tahun 2019 presentasenya adalah $1,62 \%$ atau $744 \mathrm{ibu}$ hamil dengan anemia. ${ }^{(8)}$

Anemia yakni suatu kondisi dimana jumlah dan ukuran sel darah merah atau konsentrasi hemoglobin dibawah nilai batas normal (11 gr\%) pada trimester I dan III, atau kadar nilai hemoglobin kurang dari 10,5 gr\% pada trimester II, akibatnya dapat mengganggu kapasitas darah untuk mengangkut oksigen kesekitar tubuh. ${ }^{(9)}$

Salah satu program KIA oleh Depkes RI adalah Antental Care (ANC). Terdapat $10 \mathrm{~T}$ dalam pemeriksaan ANC, yang salah satunya adalah pemberian tablet besi minimal 90 tablet selama kehamilan. Akan tetapi dalam kenyataannya, tidak semua ibu hamil yang medapatkan tablet besi meminumnya secara rutin, hal ini bisa disebabkan oleh faktor ketidaktahuan tentang pentingnya tablet besi selama kehamilan. ${ }^{(10)}$

Jumlah ibu hamil di kota Bandung pada tahun 2019 ada 45.906 ibu hamil, Cakupan pemberian 90 tablet Fe1 (30 tablet) 41.996 dan Fe3 (60 tablet) 39.251. Di Puskesmas Talagabodas pada tahun 2016 cakupan

Jurnal Penelitian Kesehatan STIKes Dharma Husada Bandung
NOMOR 1 Januari 2022

ISSN : 1979-2344

pemberian tablet besi 1 ada $1.147(83,96 \%)$

dan tablet besi 3 ada $1.101(80,60 \%){ }^{(11)}$

Faktor yang mempengaruhi kepatuhan adalah pengetahuan dan potensi sumber daya manusia. Menurut BKKBN (2011) bahwa pengetahuan ibu hamil tentang kesehatan khususnya anemia akan berpengaruh terhadap perilaku ibu hamil pada pelaksanaan program pencegahan anemia yaitu pemberian tablet zat besi. ${ }^{(5)}$

Hasil penelitian yang dilakukan oleh Kamidah Tahun 2015 dengan judul Analisa Pengetahuan Ibu Hamil Tentang Anemia Dengan Kepatuhan Mengkonsumsi Tablet Zat Besi diperoleh hasil $c^{2}$ hitung $>c^{2}$ tabel $(10,638$ $>$ 5,991) yang berarti ada hubungan pengetahuan tentang anemia dengan kepatuhan mengkonsumsi tablet zat besi. ${ }^{(12)}$

Klinik Bumi sehat Bahagia pada tahun 2018 terdapat 229 ibu hamil dengan cakupan tablet besi $229 \mathrm{ibu}$ hamil, namun terdapat 54 ibu hamil yang masih mengalami anemia, pada bulan Januari - Maret 2018 terdapat $118 \mathrm{ibu}$ hamil dengan 19 ibu hamil yang mengalami anemia, penyebab terjadinya anemia diantaranya yaitu lupa dan bermasalah dengan efek samping tablet besi, dengan begitu kepatuhan ibu hamil dalam mengkonsumsi tablet besi sangat penting untuk mengurangi terjadinya anemia.

Penelitian ini bertujuan untuk mengetahui Bagaimana Pengaruh Penyuluhan Tentang Anemia Terhadap Pengetahuan, Sikap dan Kepatuhan Ibu Hamil Dalam Mengkonsumsi Tablet Besi di Klinik Bumi Sehat Bahagia Kota Bandung. 
JURNAL SEHAT MASADA VOLUME XVI

\section{METODOLOGI}

Penelitian ini menggunakan metode quasi eksperimental dengan rancangan one group pretest postest design. Pada penelitian ini dilakukan observasi sebelum diberikan penyuluhan tentang anemia (pretest). Selanjutnya dilakukan evaluasi setelah diberikan penyuluhan (postest) untuk menilai perubahan yang terjadi serta pemeriksaan tablet besi yang telah dibagi oleh klinik Bumi Sehat Bahagia, lalu dihitung sisa dari jumlah tablet yang diberikan. Jika masih utuh atau ada sisa berarti responden tidak menunjukkan perubahan setelah dilakukan penyuluhan.

Penelitian ini merupakan penelitian kuantitatif dengan pendekatan prospektif yang artinya penelitian dimulai dari variabel penyebab atau faktor resiko, kemudian diikuti akibatnya pada waktu yang akan datang. Dengan kata lain penelitian ini berangkat dari variabel independen kemudian diikuti akibat dari akibat dari variabel independen tersebut terhadap variabel dependen. ${ }^{(33)}$

Populasi yang diambil adalah seluruh ibu hamil yang memeriksakan dirinya di Klinik Bumi Sehat Bahagia sebanyak 118 ibu hamil. Teknik pengambilan sampel penelitian ini menggunakan teknik purposive sampling yaitu pengambilan sampel didasarkan pada suatu pertimbangan tertentu yang dibuat oleh penulis sendiri, berdasarkan cirri atau sifat - sifat populasi yang sudah diketahui sebelumnya. Sampel pada penelitian ini sejumlah $32 \mathrm{ibu}$ hamil berdasarkan kriteria yaitu:

1) Kriteria inklusi adalah karakteristik umum subjek penelitian dari suatu populasi target Jurnal Penelitian Kesehatan STIKes Dharma Husada Bandung
NOMOR 1 Januari 2022 ISSN : 1979-2344

yang terjangkau akan diteliti. ${ }^{(32)}$ Kriteria inklusi pada penelitian ini :

Responden adalah ibu hamil trimester II dan III di wilayah kerja UPT Talagabodas

2) Kriteria ekslusi adalah menghilangkan/ mengeluarkan subyek yang tidak memenuhi kriteria inklusi karena berbagai hal. ${ }^{(32)}$ Adapun kriteria ekslusinya : Ibu hamil yang memiliki penyakit penyerta, misal : jantung, diabetes, penyakit menular.

Instrumen yang digunakan untuk mengukur pengetahuan dan sikap adalah kuesioner sedangkan kepatuhan responden dalam mengkonsumsi tablet besi berupa lembar observasi. Kuesioner dalam penelitian ini dibentuk kedalam 2 model, yaitu ;

1) Kuesioner untuk mengukur pengetahuan tentang anemia

Kuesioner berbentuk mutiple choice yaitu dalam pertanyaan disediakan beberapa pilihan jawaban dan responden hanya memilih satu jawaban yang benar. Kriteria penilaian adalah pemberian skor 1 untuk jawaban benar dan 0 untuk jawaban salah.

2) Kuesioner untuk mengukur sikap tentang konsumsi tablet besi

Kuesioner berbentuk skala likert yaitu disediakan beberapa pernyataan dengan pilihan jawaban sangat setuju, setuju, tidak setuju, sangat tidak setuju dan responden hanya memilih satu diantara jawaban tersebut. Kriteria penilaian skor adalah sangat setuju (SS) dengan skor 4, Setuju (S) dengan skor 3, Tidak Setuju (TS) dengan skor 2, Sangat Tidak Setuju (STS) dengan skor 1 untuk pertanyaan positif (favorable), 
JURNAL SEHAT MASADA VOLUME XVI begitu pula sebaliknya sangat tida setuju (STS) dengan skor 4, tidak setuju (TS) dengan skor 3, setuju (S) dengan skor 2, sangat setuju (SS) dengan skor 1 untuk pertanyaan negatif (unfavorable).

3) Pengukuran kepatuhan dalam konsumsi tablet besi

Menggunakan lembar observasi untuk menilai sisa tablet besi yang sudah
NOMOR 1 Januari 2022

ISSN : 1979-2344 diberikan, dibuktikan dengan melihat buku KIA pada pemberian tablet besi jika sudah diberikan sebelumnya.

Instrumen penelitian yang akan digunakan untuk penelitian dilakukan uji validitas dan reliabilitas terlebiih dahulu.

\section{HASIL DAN PEMBAHASAN}

\section{A. Hasil}

Tabel 1

Karakteristik Data Ibu Hamil di Puskesmas Talagabodas, Kota Bandung

\begin{tabular}{|c|c|c|c|c|c|}
\hline No & Item Pertanyaan & Jawaban & Jumlah Responden & $\%$ & $\mathbf{N}$ \\
\hline \multirow[t]{4}{*}{1} & Pekerjaan & IRT & 19 & 59.375 & \multirow{4}{*}{32} \\
\hline & & Wiraswasta & 8 & 25 & \\
\hline & & PNS & 3 & 9.375 & \\
\hline & & Karyawan & 2 & 6.25 & \\
\hline \multirow[t]{4}{*}{2} & Pendidikan & SD & 4 & 12.5 & \multirow{4}{*}{32} \\
\hline & & SMP & 8 & 25 & \\
\hline & & SMA/sederajat & 15 & 46.875 & \\
\hline & & SARJANA & 5 & 15.625 & \\
\hline \multirow[t]{2}{*}{3} & Usia Kehamilan & TM II & 18 & 56.25 & \multirow{2}{*}{32} \\
\hline & & TM III & 14 & 43.75 & \\
\hline \multirow[t]{2}{*}{4} & Kehamilan Ke- & $1-2$ & 14 & 43.75 & \multirow{2}{*}{32} \\
\hline & & $\geq 3$ & 18 & 56.25 & \\
\hline
\end{tabular}

Berdasarkan Tabel 1, karakteristik ibu hamil paling banyak sebagai ibu rumah tangga (59,375\%), Pendidikan SMA/sederajat (46,875\%), Usia Kehamilan TM II (56,25\%) dan Kehamilan $\geq 3(56,25 \%)$.

Tabel 2

Hasil Deskripsi Pengetahuan Ibu Hamil Sebelum dan Setelah Penyuluhan tentang Anemia

\begin{tabular}{lcc}
\hline & \multicolumn{2}{c}{ Pengetahuan } \\
\cline { 2 - 3 } & Sebelum & Setelah \\
\hline Mean & 9.25 & 13.31 \\
\hline Median & 10.00 & 14.00 \\
\hline Nilai Minimum & 3 & 7 \\
\hline Nilai Maksimum & 15 & 15 \\
\hline
\end{tabular}

Tabel 2 menunjukan hasil uji deskripsi ada perbedaan pengetahuan antara sebelum dan sesudah dilakukan penyuluhan tentang anemia terhadap ibu hamil di klinik Bumi Sehat Bahagia. Nilai mean (rata- rata) sebelum dilakukan penyuluhan adalah 9.25, sedangkan setelah dilakukan penyuluhan meningkat menjadi 13.31, nilai median adalah nilai tengah dari hasil, sebelum dilakukan penyuluhan adalah 10.00 dan setelah dilakukan penyuluhan adalah 14.00. 
Tabel 3

Hasil Data Pengaruh Penyuluhan Tentang Anemia Terhadap Pengetahuan Ibu Hamil

\begin{tabular}{lllllll}
\hline & & N & Mean & Sum & Z & $\begin{array}{c}\text { Asymp. Sig. } \\
\text { (2-tailed) }\end{array}$ \\
\hline Pengetahuan & Menurun & 1 & 27.00 & 27.00 & & \\
(setelah-sebelum) & Meningkat & 30 & 25.63 & 469.00 & & \\
& Tetap & 1 & & & & $\mathbf{. 4 . 3 4 3}$ \\
& Total & 32 & & & $\mathbf{0 0 0}$ \\
\hline
\end{tabular}

Berdasarkan tabel 3, diperoleh nilai $\mathrm{Z}=$ 4.343 dan sig. (2-tailed) $0.000 \leq 0.05$ artinya ada pengaruh penyuluhan tentang anemia terhadap pengetahuan ibu hamil dalam mengkonsumsi tablet besi di Klinik Bumi Sehat Bahagia Kota Bandung.

\section{Tabel 4}

Hasil Deskripsi Sikap Ibu Hamil Sebelum dan Setelah Penyuluhan Tentang Anemia

\begin{tabular}{lll}
\hline & \multicolumn{2}{c}{ Sikap } \\
\cline { 2 - 3 } & Sebelum & Setelah \\
\hline Mean & 29.28 & 31.72 \\
Median & 29.50 & 31.50 \\
Nilai Min & 21 & 27 \\
Nilai Max & 35 & 38 \\
\hline
\end{tabular}

Berdasarkan tabel 4, Nilai mean (rata- rata) sebelum dilakukan penyuluhan adalah 29.28, sedangkan setelah dilakukan penyuluhan meningkat menjadi 31.72, nilai median sebelum dilakukan penyuluhan adalah 29.50 dan setelah dilakukan penyuluhan adalah 31.50, nilai minimum, sebelum penyuluhan 21 sedangkan setelah penyuluhan 27 , nilai maksimum sebelum penyuluhan adalah 35 dan meningkat setelah penyuluhan yaitu 38 .

Tabel 5

Pengaruh Penyuluhan Tentang Anemia Terhadap Sikap Ibu Hamil

\begin{tabular}{lllcccc}
\hline & & N & Mean & Sum & Z & $\begin{array}{l}\text { Asymp. Sig. } \\
\text { (2-tailed) }\end{array}$ \\
\hline Sikap & Menurun & 5 & 14.20 & 71.00 & & \\
(setelah-sebelum) & Meningkat & 27 & 16.93 & 457.00 & & \\
& Tetap & 0 & & & & \\
& Total & 32 & & & $\mathbf{- 3 . 6 2 4}$ & $\mathbf{. 0 0 0}$ \\
\hline
\end{tabular}

Tabel 5 menunjukan nilai $\mathrm{Z}=-3.624$ dan sig. (2-tailed) $0.000 \leq 0.05$ disimpulkan bahwa sikap ibu hamil meningkat atau ada pengaruh penyuluhan anemia terhadap sikap ibu hamil dalam mengkonsumsi tablet besi di Klinik Bumi Sehat Bahagia Kota Bandung.
Tabel 6

Persentase Kepatuhan Ibu Hamil Mengkonsumsi Tablet Besi Setelah Penyuluhan

\begin{tabular}{lll}
\hline & $\boldsymbol{f}$ & $\%$ \\
\hline Tidak Patuh & 5 & 15.6 \\
Patuh & 27 & 84.4 \\
\hline Total & 32 & 100 \\
\hline
\end{tabular}

Berdasarkan tabel 6, ibu hamil lebih banyak yang patuh $(84.4 \%)$ meminum semua tablet besi tanpa ada sisa. 
JURNAL SEHAT MASADA VOLUME XVI

Tabel 7

Hasil Kepatuhan Ibu Hamil Dalam Mengkonsumsi Tablet Besi

\begin{tabular}{lllll}
\hline & $\boldsymbol{f}$ & Mean & Sum & Sig. \\
\hline $\begin{array}{l}\text { Patuh } \\
\text { Tidak } \\
\text { Patuh }\end{array}$ & 5 & 30.00 & 150.00 & $\mathbf{. 0 0 0}$ \\
\hline Total & 27 & 14.00 & 378.00 & \\
\hline
\end{tabular}

Tabel 7 menunjukkan sig $0.000<0.05$, disimpulkan ada pengaruh penyuluhan tentang anemia terhadap kepatuhan ibu hamil dalam mengkonsumsi tablet besi .

\section{B. Pembahasan}

\section{1) Pengaruh Penyuluhan tentang Anemia} tehadap Pengetahuan Ibu Hamil dalam

\section{Mengkonsumsi Tabet Besi}

Hasil rata - rata sebelum diberikan penyuluhan 9.25 meningkat menjadi 13.31 setelah dilakukan penyuluhan, dan hasil nilai z $=-4.343$ dan signifikansi $0.000 \leq 0.05$ (signifikan), disimpulkan bahwa pengetahuan ibu hamil meningkat. Hal ini disebabkan banyak responden yang memperhatikan materi penyuluhan menjadi lebih memahami tentang arti pentingnya mengkonsumsi tablet besi secara teratur. Dengan memperhatikan proses penyuluhan kesehatan yang diberikan, dan adanya proses tanya jawab kepada responden semakin meningkatkan pemahaman tentang kesehatan.

$$
\text { Hasil penelitian memperkuat }
$$
penelitian Rahma Noor, dkk (2013) yang meneliti Pengaruh Penyuluhan Terhadap Pengetahuan Ibu Hamil Trimester I Tentang Tablet Fe di Puskesmas Bangetayu, Semarang
NOMOR 1 Januari 2022

ISSN : 1979-2344

hasil perbedaan pengetahuan responden sebelum dan setelah dilakukan penyuluhan adalah signifikan. Dibandingkan dengan karakteristik responden (tabel 1) yang menggambarkan bahwa pekerjaan sebagai ibu rumah tangga tidak bersangkutan dengan meningkatnya pengetahuan seseorang setelah intervensi karena sebagai ibu rumah tangga lebih banyak waktu untuk mengakses berbagai informasi dari media/ sumber yang lain sebelumnya, jika dilihat mengenai pendidikan terendah responden paling banyak adalah SMA/sederajat, meningkatnya pengetahuan responden bisa karena daya tangkap responden yang lebih baik dalam mendengarkan penyuluhan, dan banyaknya ibu hamil dengan kehamilan anak yang $\geq 3$ karena sudah berpengalaman mengenai materi penyuluhan. Hal ini dibuktikan dengan jurnal yang ditulis oleh Surya berjudul Hubungan Tingat Pendidikan Dengan Keteraturan Ibu Hamil Konsumsi Tablet Fe, tingkat pendidikan dan paritas mempunyai hasil yang signifikan, disebutkan juga bahwa beberapa faktor yang mempengaruhi pendidikan adalah pengalaman, kebudayaan lingkungan sekitar, dan informasi. Selain tingkat pendidikan, pengalaman juga bisa menjadi faktor yang berpengaruh. Faktor - faktor yang mempengaruhi terhadap penyuluhan tentang anemia ibu hamil tidak dibahas secara mendalam, hal ini disebabkan karakteristik responden tidak menjadi faktor perancu dalam penelitian, peneliti hanya memfokuskan terhadap permasalahan pengetahuan, sikap dan kepatuhan ibu hamil dalam mengkonsumsi tablet besi. 
JURNAL SEHAT MASADA VOLUME XVI

Menurut WHO (2015) Penyuluhan

adalah proses perubahan perilaku dikalangan masyarakat agar mereka tahu, mau dan mampu melakukan perubahan demi tercapainya peningkatan produksi, pendapatan atau keuntungan dan perbaikan kesejahteraannya, dari pernyataan tersebut bisa disimpulkan bahwa awal perubahan dari penyuluhan agar masyarakat tahu terlebih dahulu atau dengan kata lain perubahan pengetahuan masyarakat setelah dilakukan intervensi semakin meningkat. Penyuluhan yang digunakan dalam penelitian ini yaitu dengan metode ceramah dan media power point yang ditayangkan, sehingga responden dapat memperhatikan apa yang disampaikan dan tayangan power point, selain itu dilakukan tanya jawab untuk memperdalam pengetahuan responden. Sehingga dapat diperoleh hasil nyata yang signifikan.

\section{2) Pengaruh Penyuluhan tentang Anemia} terhadap Sikap Ibu Hamil dalam Mengkonsumsi Tablet Besi

Penyuluhan anemia terhadap sikap ibu hamil semakin baik. Perubahan sikap pada responden tidak terlepas dari proses pengetahuan yang meningkat, responden bersikap menjadi baik setelah mengetahui apabila tidak merubah perilaku mengkonsumsi tablet besi akan beresiko tinggi sampai kepada kematian ibu/ janin, sama dengan jurnal yang disusun oleh Esthi. W tentang Pengaruh Penyuluhan Kesehatan terhadap Perubahan Pengetahuan dan SikapIbu Hamil Dalam Mengkonsumsi Tablet $\mathrm{Fe}$, hasil penelitian sikap peelitian menunjukkan bahwa terdapat
NOMOR 1 Januari 2022

ISSN : 1979-2344

pengaruh pemberian penyuluhan kesehatan terhadap peningkatan sikap ibu hamil dalam mengkonsumsi tablet Fe. Peningkatan sikap setelah diberi penyuluhan kesehatan sebesar 2.6\%. Distribusi karakteristik responden mayoritas memiliki anak lebih dari 3, kondisi ini menyebabkan responden sudah memiliki pengalaman yang cukup mengenai anemia dan pentingnya mengkonsumsi tablet besi karena dari pengalaman sebelumnya, sehingga berpengaruh pada sikap ibu hamil untuk mengkonsumsi tablet besi.

Peningkatan informasi responden tentang anemia dan pentingnya untuk mengkonsumsi tablet besi, berdampak pada peningkatan pengetahuan responden. Setelah memahami, maka responden akan berfikir mengenai sikap mereka yang masih menganggap bahwa anemia bukan termasuk dalam penyakit yang berbahaya sehingga tidak memerlukan untuk mengkonsumsi tablet besi secara teratur, kemudian responden dapat melakukan evaluasi pada perilaku yang kurang baik dalam mengkonsumsi tablet besi dan meningkatkan kepatuhan dalam mengkonsumsi tablet besi. Hal tersebut dikuatkan pendapat Niven 2012 dalam bukunya psikologi kesehatan yang menyatakan bahwa perubhan sikap meliputi tahap pertma yaitu unfreezing, yaitu ketika responden menyadari bahwa tindakannya kurang tepat dalam mengkonsumsi tablet besi. Tahap kedua yaitu changing (perubahan) yaitu setelah responden menyadari bahwa tindakannya selama ini salah, maka terbentuk sikap baru dalam mengkonsumsi tablet besi. Tahap ketiga yaitu refreezing, tahap ini Jurnal Penelitian Kesehatan STIKes Dharma Husada Bandung 
JURNAL SEHAT MASADA VOLUME XVI responden mengevaluasi sikapnya terhadap penaltalaksanaan konsumsi tablet besi.

\section{3) Kepatuhan Ibu Hamil dalam}

\section{Mengkonsumsi Tablet Besi}

Ibu hamil patuh dalam mengkonsumsi tablet besi, kepatuhan dalam mengkonsumsi tablet besi dilihat dari sisa tablet besi yang diberikan, dibuktikan dengan laporan buku KIA tentang pemberian tablet besi jika sudah dikonsumsi sebelumnya. Hal ini dibuktikan dengan jurnal yang ditulis oleh Rena, dkk berjudul Hubungan Pengetahuan dan Sikap Ibu Hamil Dengan Kepatuhan Dalam Mengkonsumsi Tablet Besi di Wilayah Kerja Puskesmas Seberang Padang Tahun 2013 diperoleh $\mathrm{p}$ sebesar $0,021 \quad(\mathrm{p}<0,05)$ pada variable pengetahuan yang berarti terdapat hubungan yang bermakna antara pengetahuan dengan kepatuhan ibu hamil dalam mengkonsumsi tablet besi, serta diperoleh nilai p sebesar 0,001 $(\mathrm{p}<0,05)$ pada variable sikap yang berarti bahwa terdapat hubungan yang bermakna antara sikap dan kepatuhan ibu hamil dalam mengkonsumsi tablet besi.

Kepatuhan adalah perilaku individu (misalnya: minum obat, mematuhi diet, atau melakukan perubahan gaya hidup) sesuai anjuran terapi dan kesehatan. ${ }^{(22)}$ Jadi, sangat jelas tergambarkan bahwa kepatuhan dalam mengkonsumsi tablet besi bisa dilihat pentingnya tablet besi dkonsumsi sesuai anjuran 1x sehari oleh ibu hamil yang bukan penderita anemia, cara meminum yang benar, dan lain - lain. Kondisi ini menunjukkan bahwa dari pengetahuan yang semakin meningkat dapat mempengaruhi sikap menjadi
NOMOR 1 Januari 2022 ISSN : 1979-2344

lebih baik. Sikap yang baik ini kemudian diimplementasikan dalam perilaku (kepatuhan) responden untuk mengkonsumsi tablet besi secara teratur. Perilaku responden ini memperkuat pendapat Notoatmodjo (2012), perilaku merupakan determinan kesehatan yang menjadi sasaran dari promosi atau pendidikan kesehatan. Dengan kata lain promosi atau pendidikan atau penyuluhan kesehatan bertujuan untuk mengubah perilaku (behavior change).

Setelah dilakukan penyuluhan pada penelitian ini, masih ada 5 responden yang tidak patuh dalam mengkonsumsi tabket besi, dikarenakan masih adanya rasa enggan terhadap bau tablet besi, banyaknya tablet besi yang diterima dan masih menganggap tablet besi sebagai obat untuk menyembuhkan orang yang sakit, jika responden merasa dirinya tidak sakit berarti responden tidak perlu untuk mengkonsumsi tablet besi yang telah diberikan oleh petugas kesehatan. Namun 27 responden menunjukkan bahwa pengetahuan responden mengenai anemia meningkat dan sikap responden menjadi lebih baik, sehinggadihasilkan sebagian besar responden memiliki tingkat kepatuhan tinggi dalam mengkonsumsi tablet besi. Kepatuhan ibu hamil dalam mengkonsumsi tablet besi sangat dipengaruhi oleh diri sendiri dalam menyadari pentingnya tablet besi bagi dirinya dan bayinya terutama untuk kesehatannya agar selalu dalam kondisi prima, maka mereka akan mengkonsumsi tablet besi sesuai dengan anjuran yang diberikan. 
JURNAL SEHAT MASADA VOLUME XVI

\section{KESIMPULAN}

Terdapat pengaruh penyuluhan tentang anemia terhadap pengetahuan ibu hamil. Terdapat Perubahan rata - rata sikap responden sebelum dilakukan penyuluhan sebelum dan setelah dilakukan penyuluhan.

\section{DAFTAR PUSTAKA}

(1) WHO. The Prevalence of Anemia in 2011. WHO global database on anemia geneva. World health organization. 2015

(2) Kementrian Kesehatan RI, 2015. Angka kematian bayi (AKB)

(3) Data Dinas Kesehatan Provinsi Jawa Barat. Angka Kematian Ibu (AKI) dan Angka Kematian Bayi (AKB) 20142015. Profil Dinas Kesehatan Jawa Barat

(4) Wikipedia.org.wiki. Tujuan Pembangunan Milenium

(5) Prawirohardjo, 2009. Ilmu Kebidanan. Jakarta : YBP - SP

(6) World Health Organization. 2014. International Statistical Classification of Disease and Related Health Problems Tenth Revision Volume 2 second edition. Geneva: World Health Organization.

(7) Riskesdas , 2013. Prevalensi Anemia pada Ibu Hamil di Indonesia. Jakarta

(8) Data Dinas Kesehatan Jawa Barat. 2016. Angka Kejadian Anemia Kota Bandung

(9) Pusdiknakes, 2011. Pengertian Anemia Menurut Para Ahli. Jakarta

(10) Departemen Gizi dan Kesehatan Masyarakat FKM UI (2012). Gizi dan Kesehatan Masyarakat. Jakarta : PT. Raja Grafindo Persada.

(11) Data Dinas Kesehatan. 2016. Cakupan Tablet Fe Kota Bandung. Profil Dinas Kota Bandung

(12) Kamidah., (2015), Analisa Pengetahuan Ibu Hamil Tentang Anemia Dengan Kepatuhan Mengkonsumsi Tablet Zat Besi, Vol. 12, pp $44-57$.
NOMOR 1 Januari 2022

ISSN : 1979-2344

(13) UPT Talaga Bodas.2016. Profil Kesehatan Puskesmas Talaga Bodas. Bandung

(14) Notoatmodjo, S. (2010). Promosi Kesehatan dan Ilmu Perilaku. Jakarta : Rineka Cipta.

(15) Syarifudin dan Fratidhina, 2009. Media Promosi Kesehatan. Jakarta : PT Rineka Cipta.

(16) Effendy, N. (2010). Dasar - dasar Keperawatan Kesesahatan Masyarakat. Yogyakarta : Rineka Cipta

(17) WHO, 2011. Nutrition : Iron Deficiency Anemia. www.who.Int

(18) Sandra, F. et.al. (2016), Gizi Ibu Dan Bayi, Raja Grafindo Persada, Jakarta.

(19) Manuaba, 2010. Pengantar Kuliah Obstetri. Jakarta : EGC

(20) Atikah Proverawati, 2011. Klasifikasi Anemia dalam Kehamilan

(21) Taufan, N. (2012), Patologi Kebidanan, Nuha Medika, Yogyakarta.

(22) Anesmg. Tablet Fe Zat Besi. 2014. https://.wordpress.com/2014/05. Di download tanggal 20 Oktober 2017.

(23) Florencia, Eddy, Hermie., (2015), Profil Zat Besi (Fe) Pada Ibu Hamil Dengan Anemia Di Puskesmas Bahu Manado.

(24) Amsal Bakhtiar. 2008. Filsafat Ilmu. Ed. Rev. Jakarta : PT Raja Grafindo Persada

(25) Soekanto, Soerjono. Sosiologi Suatu Pengantar. Jakarta : Rajawali Pers. 2012

(26) Notoatmodjo (2012). Metodologi Penelitian Kesehatan. Ed. Rev. Jakarta : Rineka Cipta

(27) Azwar, S. 2011. Sikap dan Perilaku. Dalam : Sikap Manusia Teori dan Pengukurannya. $2^{\text {nd }}$ ed. Yogyakarta : Pustaka Belajar, 3 - 22

(28) Notoatmodjo (2010). Konsep Perilaku Kesehatan dalam : Promosi Kesehatan Teori dan Aplikasi. Jakarta : Rineka Cipta

(29) Abu Ahmadi, 2013. Psikologi Belajar. Jakarta : Rineka Cipta 
JURNAL SEHAT MASADA VOLUME XVI

(30) Kozier. (2010). Buku Ajar Praktik Keperawata Klinis. Edisi 5. Jakarta : EGC

(31) Sarafino dalam buku Yetti, dkk 2011. Pengertian Kepatuhan

(32) Menurut Sacket dalam Niven 2012. Psikologi Kesehatan. Jakarta : EGC

(33) Suparyanto. (2010). Konsep kepatuhan. Diakses pada tanggal 24 Februari 2018
NOMOR 1 Januari 2022

ISSN : 1979-2344

(34) Syakira, G. (2009). Konsep kepatuhan. http://www.google.com/konsepkepatuha n. Diakses tanggal 27 Februari 2018

(35) Akhmad Sudrajat. Taksonomi Perilaku Individu. 2008. https://wordpress.com. Di download tanggal 21 Oktober 2017

(36) Sugiyono.2010.Metode Penelitian Kuantitatif, Kualitatif dan $R \& D$.Bandung $\quad$ : $\quad$ Alfabeta 